tral range of the eastern peninsula of New Guinea. $\mathrm{Mr}$. Forbes has been allowed $400 \%$. by the British Association and 250 . by the Royal Geographical Society towards the expense of the expedition. The party will start early in December, though it is not expected to get into active working before May next, in consequence of the necessity for procuring trusty carriers from the Moluccas. Mr. Forbes will break his journey at Batavia, in order to proceed to Amboyna, where he hopes to find his men. He will then return to Batavia, and sail for Thursday Island, proceeding thence to Port Moresby. He proposes to ascend the course of one of the rivers which flow from the mountains to Redscar Bay. Should the natives prove fricndly and the food-supplies sufficient, $\mathrm{Mr}$. Forbes does not despair of reaching the other coast of the peninsula; but in any case the exploration of the Mount Owen Stanley Range would be of itself a satisfactory achievement. The mountain travelling is declared to be dangerous to any but very experienced travellers.

NEws has reached St. Petersburg from Col. Prjevalsky, the indefatigable explorer in Thibet, whose expedition appears to be distinguishing itself in feats of arms as well as discoveries of science. A telegram viâ Kiatcha, dated August 20, says :"The difficult task of the expedition has been successfully accomplished. During the three summer months we traversed 1000 versts of North-Eastern Thibet. We first descended from Zaidam, 400 versts south, over the sources of the Yellow River to the Blue River, which it was found impossible to cross, and then we explored the large lakes in the upper course of the Yellow River. One lake was named 'Russian,' another 'Expedition' Lake. Their height was I3,500 feet, the surrounding country being a mountain plateau 1000 feet higher. Along the Blue River lies a mountainous, but woodless and Alpine country. The climate of the localities passed through was terrible. The whole of the summer wa; cold, with rain and snow; at the cnd of May there was sharp frost, in July we had snowstorms like those of winter, while the amount of alluvium deposited by south-western monsoons from the Indian Ocean is so great that in summer Northem Thibet is converted into an almost continuous marsh. Wild animals and fish are abundant, the birds and flora poor, but original. The Tanguts live on the Blue River, and near the lakes of the Yellow River. Here we were twice attacked by about 300 mounted marauders, and the heroic conduct of my companions, armed with Berdan rifles, saved the expedition. We soon repulsed the first attack on July 25, and subsequently destroyed the Tangut camp A week later a fresh party from another Tangut tribe attacke- us. For two hours on the banks of the Yellow River we repelled the mounted brigands with repeated volleys from our rifles; and when we took the offensive the Tanguts retreated behind the knolls, and in turn began volley-firing. We were most fortunate, all coming off safe and sound, only two of our horses being wounded, while forty of the brigands were killed and wounded in the two encounters. We now go to Western Zaidam. We shall establish a depot at Hast, and during the winter explore the surrounding localities."

DR. Gerhakn Rohlfs leaves for the West Coast of Africa by one of the German war-ships under Admiral Knori, and has been intrusted with a special mission by the German Government.

CAPT. BlCKER and some other Belgian officers are about to proceed to Zanzibar, thence to start for Lake Tanganyika. They intend to cross this lake, and to found a station on its western shore. Thus the line of stations acioss Africa, which the International African Society has planned, will be completed. On the eastern side of Lake Tanganyika, between this and the seacoast, there are four stations: Kondoa, in Usagara ; Tabora, in Unyanyembe; Kakoma, in Uganda ; and Karema, on the shore of the lake. On the western side there are over fifty stations between the lake and the Atlantic.

THE subject of trade-routes into South-Western China is now engaging attention in France, and has caused much discussion in the periodical press. The various methods of reaching Szechuan and Vunnan which have from time to time been suggested by explorers are dismissed in their turn as impracticable. From the side of India we have the Brahmaputra, which is navigable almost to the Chinese frontier, and the Irrawaddy viâ Bahmo. These are described as useless on account of the obstacles offered by lofty and almost impassable ranges of mountains; the Meinam from Bankok would only land us in the Shan States; the Meikong, through Cambodia, was tried by Lagrée, but was found quite unfit for navigation on account of its numerous rapids and cataracts. In China we have the Sikiang-which offers an almost straight line from Canton into Southern China, and was followed by Mr. Colquhoun in his recent attempt to cross through the Shan States into British Burmah-and the Yang-tsze-kiang, but both of these routes, according to French writers, are closed to trade by Chinese hostility Thus every possible route has been tried and found wanting, with one exception, viz. that by the Songkoi or Red River of Tonquin. By means of this new possession of France the trade of the two great provinces of South-Western China, say the French writers, can be tapped, and in no other way. Their wealth, it is said, will be poured down the valley of the Red River into the hands of the French traders at Hanoi and Haiphong. With regard to routes mentioned only to be dismissed as impossible, nothing need be said here. Their merits and defects may be found described in a score of English works by explorers on the spot; but so far as the Red River is concerned, no proposition either way can be laid down with safety. Beyond Hanoi it is but little known, and its upper waters above Honghoa are almost wholly unknown to Europeans. But one Frenchman has ever ascended or descended the river, and when M. Dupuis made his courageous journeys more than ten years ago, he did so under circumstances which rendered geographical observation impossible. All that M. Dupuis can say (and European knowledge is confined to his information) is that with an escort, and with Chinese passports, he was able to come down the river in a small junk, and to ascend it again with several junks laden with arms and ammunition. Even at the present moment the whole river from Honghoa to Laokai on the Chinese frontier is in the hands of the Black Flags. Moreover it has been stated that after leaving the Red River the route would have to cross a lofty mountain range, and pass through the most desolate region in Yunnan. The river may offer an excellent trade route; but in the present state of our geographical knowledge of Upper Tonquin all that can be said with certainty is that nobody knows whether it is so or not. Happily the French lose no time in thoroughly studying the countries which they occupy, and as soon as a state of peace has been reached in Indo.China we shall be in a position to decide the question; until then anything written about the navigation of the Red River above Honghoa is mere speculation, and valueless for practical purposes.

THE last number of the Izvestia of the Russian Geographical Society contains three interesting papers by M. D. Ivanoff on the Pamir, embodying the results of the last year's expedition, and giving a lively summary of our present knowledge as to this very interesting region. A E. Regel contributes to the same number a note on his journey to the Shugnan; A. Wysheslavtseff describes the burial customs of the Tchuvashes; and P. A. Putyatin contributes a note on the pottery of the Stone Age. The same issue contains, moreover, accounts of the geodetical and cartographical work done in $\mathbf{I} 883$ by the military top igraphers and by the Hydrographical Department, and several notes.

\section{NATURAL SCIENCE IN SCHOOLS}

HOWEVER fully it may be admitted by the few that it is important, nay essential, that all members of the community, whatever their station or occupation, should during their sch sol career reccive some instruction in the elements of natural science, the general public have not as yet had brought home to them with sufficient clearness that, just as a knowledge of foreign languages is essential to all who are brought into intercourse with foreigners, so in like manner is a correct knowledge of the elements of natural science of direct practical value to all in their daily intercourse with Nature, apart from the pleasure which such knowledge affords. In fact, judged from a purely utilitarian standpoint, the advantages to be derived from even the most elementary acquaintance with what may be termed the science of daily life are so manifold tha+, if once understood by the public, the claims of science to a place in the ordinary school course must meet with universal recognition. To quote Huxley ${ }^{2}$ :

r "On the Teaching of Natural Science as a Part of the Ordinary School Course, and on the Method of Teaching Chemistry in the Introductory
Course in Science Classes, Schools and Colleges." Paper read at the EduCourse in Science Classes, Schools and Colleges." Paper read at the EduArmstrong, Ph.D, F.R.S., Sec.C.S., Professor of Chemistry in the Finsbury

Technical College.

2 This writer's "Introductory" to Macmillan's Science Primers, and his "Physiography: an Introduction to the Study of Nature," should be studied by all who wish to know what science is and how it should be taught. 
" Knowledge of Nature is the guide of practical conduct; any one who tries to live upon the face of this earth without attention to the laws of Nature will live there for but a very short time, most of which will be passed in exceeding discomfort: a peculiarity of natural laws, as distinguished from those of human enactment, being that they take effect without summons or prosecution. In fact, nobody could live for half a day unless he attended to some of the laws of Nature; and thousands of us are dying daily, or living miserably, because men have not yet been sufficiently zealous to learn the code of Nature."

But it is also and mainly on other and far higher grounds that we should advocate universal practical teaching of the elements of natural, and more particularly of so-called physical, science: viz. that it tends to develop a side of the human intellect which, I believe I am justified in saying, is left uncultivated even after the most careful mathematical and literary training: the faculty of observing and of reasoning from observation and experiment. It is entirely from this latter point of view that $I$ shall venture to propund a scheme for teaching the elements of that branch of physical science with which I am most intimately acquainted.

This Exhibition affords some few noteworthy illustrations of the way in which the importance of teaching the elements of natural science has received practical recognition in our schools. Thus we have indications of the work being done by the Birmingham School Board; the London School Board call attention to their system of training pupil-teachers in science; $\mathrm{Mr}$. Robins shows plans of one of the best, if not the best equipped school chemical laboratory-that of the Manchester Grammar School. Also, it is well known that at many of the larger schools, such as Clifton College, Eton, Harrow, Rughy, St. Paul's, Giggleswick, and the North London Collcgiate School for Girls, ample provision is made for tcaching one or mor branches of natural science; and not a few other examples might be quoted. But in how large a proportion of the schools through. out the country is such training neglected? and there is much cause for complaint in the fact that, in those schools in which science is taught, it is after all in most cases but a lind of "refuge for the destitute," only those who have failed on the classical side and those judged to be inferior in intellect being turned over to the so-called modern side. This is prohably due to a varicty of canses: to the ignorance already referred to of the public of the importance and valuc of such training, or it would be clemanded of the schools; to the ignorance of even the barest elements of science of the majority of teachers in charge of schools; to the want of good science teachers and of suitable books; to the supposed expense of teaching science and lastly - and I belicve this to be the most important of all the causes which opcrate against the teaching of science-to the imperfection of our method of teaching: there can be little doubt, in fact, that the majority of teachers of the generally recognised subjects who have themselves no scientific knowledge see clearly cnough that very little good comes of teaching science in the manner in which it is commonly taught in schools.

The great objection to the method at present in vogne appears to me to be that it is practically the same whether science is taught as a part of the general school course, or whether it is taught professionally; in other words, a lad studies chemistry, for example, at school in just the same way as at a science college, the only difference being that he does not carry his studies so far at school as at collcge. This, I believe, is the primary fault in our present system. In my opinion, no single branch of natural science should be selected to be taught as part of the ordinary school course, but the instruction should comprise the elements of what I have already spoken of as the science of daily life, and should include astronomy, hotany, chemistry, geology, mechanics, physics, physiology and zoology - the olle podrida comprehended by Huxley under physiography, but which is perhaps more happily expressed in the German word Naturkunde - in so far as is essential to the understanding of the ordinary operations and objects of Nature, the teaching from beginning to end being of as practical a character as possible, and of such a kind as to cultivate the intelligence and develop the faculties of observing, comparing and reasoning from observation and the more technical the course the better. The order in which these subjects should be introduced is matter for discussion ; personally, I should prefer to begin with botany, and to introduce as soon as possible the various branches of science in no particular order but that best suited to the understanding of the various objects or phenomena to which the teaching for the time being had reference. The extent to which instruction of this kind is given must entirely depend on the class of scholars.
There are few teachers capable of giving such instruction, and fewer books of a character suited to ordinary requirements. The development of such a system will, in fact, require the earnest co-operation of a number of specialists; but apart from the difficulty of securing efficient co-operation, there is no reason why some such scheme should not be elaborated at no distant date. If action is to be taken, however, there must be no delay, or the opportunity will be lost. I trust that this meeting will be prepared to give much attention to this question, and that it may be possible to continue the discussion on other platforms, as it is fundamentally important and deserving of the most serious consideration of educationalists. No doubt it will be said that the object of introducing the teaching of science into the school course is to afford mental training of a particular character, not the inculcation of useful knowledge, and that this end can be secured by teaching well some one branch of science. Admitting that this has been the case, however, there is no reason why it should be in the future : if while developing the intellect it be possible-and it certainly is-to impart much valuable information; and if-as it certainly is-the teaching be rendered easier and more attractive because it has direct reference to the familiar objects and operations of Nature. We caunot, indeed, any longer afford to grow up ignorant of all that is going on around us, and without learning to use our eyes and our reasoning powers ; we cannot afford to be unacquainted with the fundamental laws of health ; but we must ever remember "that knowlerlge of Nature is the guide of practical conduct," and no effort must be spared to render our system of education an effectual preparation and truly adapted to the exigencies of practical life. The female educators appear already to have grasped the importance of such teaching, and under the guise of domestic economy much that I advocate is being taught in girls' schools; it is to be hoped that ere long something akin to the domestic economy course in girls' schools will find a place in boys' schools.

To pass now to the consideration of the mode of teaching my own special subject in science classes, such as those held under the auspices of the Science and Art Department, and in the introductory course for students in science schools and colleges generally. To deal first with the former. Inspection of the syllabus for the elementary stage, together with the study of the examination papers of the past few years, will show that the student is mainly required to have an elementary knowledge of the methods of preparing, and of the properties of, the commoner non-metallic elements and their chief compounds. There is thus practically no distinction to be drawn between the knowledge required of students under the Science and Art Department, and of those who are making the study of chemistry the business of their lives. But surely it is not the function of the Science and Art Department to train up chemists, and I am satisfied that it is neither their desire nor their intention to do so ; their object undoubtedly is to encourage the teaching of chemistry as a means of cultivating certain faculties, and in order that the fundamental laws of chemistry may be understood and their commoner applications realised. It is not difficult to understand how the system has grown up and why it is maintained ; I not believe it is because the Department consider it a satisfactory one; but they know full well that a better system is not yet developed, and that it would be unwise to legislate far in advance of the intelligence and powers of the majority of the teachers. With all deference, however, I venture to add that the programme has been drawn up too much from the point of view of the specialist, and that too little attention has been devoted to it from the point of view of the educationalist. The course I am inclined to advocate would be of a more directly useful character. There is no reason why in the beginning attention should be confined to the non-metals, especially when certain of the metals enter so largely into daily use; and provided that it involve no sacrifice of the opportunities of developing the faculties which it is our special object to cultivate by the study of chemistry, there is no reason against, but every reason for, selecting subjects of every-day importance rather than such as are altogether outside our ordinary experience, such, for example, as the oxides of nitrogen : even chlorine, except in relation to common salt, might be omitted from special study. The presumed distinction between so-called inorganic and organic chemistry should be altogether put aside and forgotten, and the elements of the chemistry of the carbon compounds introduced at a very early stage in order that the phenomena of animal and plant life might come under consideration. To give the barest possible outline of a programme, I would include such subjects as the following in the syllabus :-

The chemistry of air, of water, and of combustion; the 
distinction between elements and compounds ; the fundamental laws which regulate the formation of compounds and the chemical action of bodies upon one another (i.e. the nature of so-called chemical change); the chemical properties of the metals in ordinary use, with special reference to their uses and the action upon them of air, water, \&c. ; the composition of natural waters ; the distinction between fats, carbohydrates and albuminous substances in so far as is essential to the understanding of the relative values of different foods and respiration and growth in animals and plants (outlines of the chemistry of animal and plant life, in fact); the nature of the processes of fermentation, putrefaction, and decay.

The instruction in these subjects should in all cases be 1m. parted by means of object-lessons and tutorial classes; lectures pure and simple should, as far as possible, be avoided. The students should by themselves go through a number of practical exercises on the various subjects. I would abolish the teaching of tables for the detection of simple salts, the teaching of analysis as at present conducted being, I believe, in most cases of very little if any use except as enabling teachers to earn grants.

In schools and colleges in which chemistry is taught as a science, and ostensibly with the object of training young people to be chemists, it is the almost invariable practice that the student first devotes more or les $;$ time to the preparation of the commoner gases, and then proceeds to study qualitative analysis ; quantitative determinations are made only during the later period of the course. I believe that the system has two great faults : it is too mechanical, and does not sufficiently develop the faculty of reasoning from observation; and actual practice in measurement is introduced far too late in the course. It is of great importance that the meaning of the terms equivalent, atomic weight, molecular weight, should be thoroughly grasped at an early stage, but according to my experience this is very rarely the case ; there is no such difficulty, however, if the beginner is taught to make a few determinations himself of equivalents, \&c., as he very well may be. It is not necessary here to enter into a more detailed criticism, but I propose instead to give a brief description of a modification of the existing system which in my hands, in the course of about four years' experience, has furnished most encouraging results, and which I venture to think is worthy of an extended trial.

Instead of merely preparing a variety of gases, the student is required to solve a number of problems experimentally : to determine, for example, the composition of air and of water ; and the idea of mea surement is introduced from the very beginning, as the determination is made quantitatively as well as qualitatively. Each : tudent receives a paper of instructions -two of which are printed as an appendix to this paper-which are advisedly made as bare as possible so as to lead him to find out for himself, or inquire, how to set to work ; and he is particularly directed that, having made an experiment, he is to enter in his notebook an account of what he has done and of the result, and that he is then and there to ask himself what bearing the result has upon the particular problem under consideration, and, having done so, he is to write down his conclusion. He is thus at once led to consider what each experiment teaches: in other words, to reason from observation. Apart from the mental exercise which this system affords, if the writing out of the notes be properly supervised, the literary exercise which it also affords is of no mean value.

In illustration, I may here very briefly describe the manner of working out the second problem in the course. The problem being to determine the composition of water, the student receives the instruction :- I. Pass steam over red-hot iron brads, collect the escaping gas, and apply a light to it. (N.B. The gas thus produced is called hydrogen.) $\mathrm{Hc}$ is provided with a very simple apparatus, consisting of a small glass flask contain ing water, joined by a narrow bent glass tube to an iron tube (about 9 inches long and $\frac{1}{2}$ to $\frac{3}{4}$ inch wide) in which the brads are placed, a long glass tube suitably bent for the delivery of the gas being attacbed to the other end of the iron tube. Plaster of Paris is used instead of corks to make the connections with the iron tube. The iron tube is supported over a burner, and heated to redness; the water in the flask is then heated to boiling, and the stcam thus generated is passed over the brads; the escaping gas is collected over water in the usual manner. Having made this experiment, and observed that, on passing steam over red-hot iron, the gas hydrogen is produced, the student proceeds to consider the bearing of this observation. The hydrogen must obviously be derived either from the water or from the iron, if not from both. Those who already know that iron is iron, so to speak, at once infer that the hydrogen is derived from the water : it is, however, pointed out that, even if it be known that iron is a simple substance, this observation taken alone does not prove that hydrogen is contained in water.

2. The student next learns to prepare hydrogen by the ordinary method of dissolving zinc in diluted sulphuric acid, and makes a few simple experiments whereby he becomes acquainted with the chief properties of the gas.

3. Having done this, he is instructed " to burn dry hydrogen at a glass jet underneath a cold surface and to collect and examine the product." The product is easily recognised as water, and the immediate answer to the question, "What does this observation teach ?" is, that since iron is absent, taken in conjunction with Experiment $\mathbf{I}$, the production of water on burning hydrogen in air, the composition of which has already been determined, is an absolute demonstration that hydrogen is contained in water.

4. Having previously studied the combustion of copper, iron, and phosphorus in air, and having learnt that when these substances burn they enter into combination with the oxygen in air, the student is also led to infer from the observation that hydrogen burns in air producing water, that most probably it combines with the oxygen, and that water contains oxygen besides hydrogen. It may be however, it is then pointed out, that the hydrogen, unlike the phosphorus, \&c., combines with the nitrogen instead of with the oxygen, or perhaps with both. $\mathrm{He}$ is therefore instructed to pass oxygen over heated copper, weighing the tube before and after the operation, and subsequently to heat the "oxide of copper" in a current of hydrogen. He then observes that water is formed, the oxygen being removed from the copper: and since nitrogen is absent, it follows that water consists of hydrogen and oxygen, and of these alone.

5. By repeating this last experiment so as to ascertain the loss in weight of the copper oxide tube and the weight of water produced, the data are obtained for calculating the proportions in which hydrogen and oxygen are associated in water.

In practice the only serious difficulty met with has been to induce students to give themselves the trouble to consider what information is gained from a particular observation; to be properly inquisitive, in fact. I cannot think that this arises, as a rule, from mental incapacity. When we consider how the child is always putting questions, and that nothing is more beautifully characteristic of young children than the desire to know the why and wherefore of everything they see, I fear there can be little doubt that it is one of the main results - and it is indeed a lamentable result-of our present school system that the natural spirit of inquiry, inherent to a greater or less extent in every member of the community, should be thus stunted in its growth, instead of being carefully developed and properly directed.

Having in the manner which I have described studied air, water, the gas given off on heating common salt with sulphuric acid, and the ordinary phenomena of combustion, the student next receives a paper with directions for the comparative study of lead and silver (see Appendix). The experiments are chosen so as to afford an insight into the principles of the methods ordinarily employed in qualitative and quantitative analyses, and the student who has conscientiously performed all the exercises is in a position to specialise his studies in whatever direction may be desirable.

The system I have thits advocated undoubtedly involves far more trottble to the teacher than that ordinarily followed, but the student learns far more under it, and I assert with confidence that the training is of a far higher order, and also of a more directly useful character. I believe it to be generally applicable, and that it would be of special advantage in those eases in which only a short time can be devoted to the study of chemistry, as in evening classes and medical schools. At present the only practical teaching vouchsafed to the majority of students in our large medical schools is a short summer course, during which they are taught the use of certain analytical tables: as a mental exercise the training they receive is of doubtful value ; the knowledge gained is of little use in after life, and the course ccrtainIy ought not to be dignified by being spoken of as a course of Practical Chemistry ; test-tubing is the proper appellation. It is not a little remarkable also that even the London University Syllabus nowhere specifies that a knowledge even of the elentents of quantitative analysis will be required of candidates either at the Preliminary Scientific or First M. B. Examination, and this, too, when, as is well known, an analysis to be of any practical 
value must almost invariably be quantitative. It is little less than a disgrace to the medical profession that a subject of such vital imp rrtance as chemistry should be so neglected.

If, however, we are to make any change in our method of teaching science, if we are to teach science usefully throughout the country, two things are necessary : teachers of science must take counsel together, and the examining boards must seriously consider their position. There can be little doubt that in too many cases the examinations are suited to professional instead of to educational requirements ; and that the professional examinations are often of too general a character, and do not sufficiently take into account special requirements.

\section{APPENDIX}

Problem: to Determine the Composition of Arr

N.B.-Immediately after performing cach experiment indicated in this and subsequent papers, write down a careful description of the manner in which the experiment has been done, of your observations and the result or results obtained, and of the bearing of your observations and the result or results obtained on the problem which you are engaged in solving. Be especially on your guard against drawing conclusions which are not justificd by the result of the experiment; but, on the other hand, endeavour to extract as much information as possible from the experiment.

r. Burn a piece of $d r y$ phosphorus in a confined volume of air, i.e. in a stout Florence flask closed by a caoutchouc stopper. Afterwards withdraw the stopper under water, again insert it when water ceases to enter and measure the amount of water sucked in. Afterwards determine the capacity of the flask by filling it with water and measuring this water.

N.B.-The first part of the experiment requires care and must be done under direction.

2. Allow a stick of phosphorus lashed to a piece of stout wire to remain for some hours in contact with a known volume of air confined over water in a graduated cylinder. After noting the volume of the residual gas, introduce a burning taper or wooden splinter into it.

N.B. - The residual gas is called nitrogen.

3. Burn a piece of dry phosphorus in a current of air in a tube loosely packed with asbestos. Weigh the tube, \&c., before and after the experiment.

4. Repeat Experiment 2 with iron horings moistened with ammonium chloride solution. Preserve the residual gas.

5. Suspend a magnet from one arm of a balance; having dipped it into finely divided iron, place weights in the opposite pan, and when the balance is in equilibrium, set fire to the iron.

6. Pass a current of dry air through a moderately heated tube containing copper. Weigh the tube before and after the experiment; also note the alteration in the appearance of the copper.

7. Strongly heat in a dry test tube the red substance obtained by heating mercury in contact with air. At intervals plunge a glowing splinter of wood into the tube. Afterwards note the appearance of the sides of the tube. (Before performing this experiment ask for directions.)

N. R. - The gas obtained in this experiment is named oxygen.

8. Hcat a mixture of manganese dioxide and potassium chlorate in a dry test tube, and at intervals plunge a glowing splinter into the tube. This experiment is to acquaint you with an easy method of preparing oxygen in quantity.

9. Prepare oxygen as in Experiment 8, and add it to the nitrogen from Experiment 4 in sufficient quantity to make up the bulk to that of the air taken for the latter experiment. Test the mixture with a burning taper or splinter.

10. Dissolve copper in nitric acid and collect the escaping gas (nitric oxide); add some of it to oxygen and some of it to air.

II. Fill a large flask provided with a well-fitting caoutchouc stopper and delivery tube with ordinary tap water and gradually heat the water to the boiling-point; collect the gas which is given off in a small cylinder and add nitric oxide to it. Also collect a sufficient quantity in a narrow graduated cylinder and treat it as in Experiment 2.

\section{Comparative Stuny of Silver and Lead}

Silver.-Symbol, AG. (Argentum). Atomic weight, 107.67. Specific heat, '0570I.

LEAD.-Symbol, Pr. (Plumbum). Atomic weight, 206.47. Specific heat, ${ }^{\circ} \mathbf{3} 140$.

I. Determine the relative density of lead and silver at a known temperature by weighing in air and in water.
2. Separately heat known weights of lead and silver for some time in the air, allow to cool, and weigh.

3. Separately convert known weights of lead and silver into nitrates, and weigh the latter. From the data thus obtained calculate the equivalents of lead and silver.

4. Convert the known weights of nitrates thus obtained into chlorides, and weigh the latter.

5. Compare the action on lead and silver of chlorhydric acid; of dilute and concentrated sulphuric acid, using the acid both cold and hot ; and of cold and hot nitric acid.

6. Using solutions of the nitrates, compare their behaviour with chlorhydric and sulphuric acids, hydrogen sulphide, potassium iodide, and potassium chromate. Ascertain the behaviour of the precipitate formed by chlorhydric acid when boiled with water, and when treated with ammonia solution.

7. Compare the behaviour of lead and silver compounds on charcoal before the blowpipe.

8. Tabulate the results of your experiments with lead and silver in parallel columns.

9. Ascertain whether the substances given you contain lead or silver.

Io. Determine silver in an alloy of lead and silver by cupellation.

I I. Study the method of determining silver volumetrically by means of a standard solution of ammonium thiocyanate. Determine the percentage of silver in English silver coinage.

x2. Determine silver as chloride by precipitation.

13. Dissolve a known weight of lead in nitric acid, precipitate it as sulphate, collect and weigh the latter.

I4. What are the chief ores of lead and silver? How are lead and silver extracted from their ores? How is silver separated from lead? How is it separated from burnt Spanish pyrites? What are the chief properties and uses of lead and of silver? State the composition of the chief alloys of lead and silver.

\section{TRANSACTIONS OF THE NEW ZEALAND INSTITUTE}

VOLUME XVI. of the Transactions and Proceedings of the New Zealand Institute contains the more important memoirs laid before its eight incorporated Societies during the year 1883 and the first weeks of 1884 . It forms a bulky volume of about $65^{\circ}$ pages, and is illustrated by 44 plates. It speaks a great deal for the energy of the ablc editor, Dr. James Hector, F.R.S., that he has in so short a time reduced such a mass of matcrial into order, and that the volume should be issued in May of this year. While we think the illustrations still leave something to be desired as to their general style and execution, this volume is exiremely creditable to the colony, and the amount of accurate research recorded will, if continued, soon make New Zealand one of the most completely investigated regions of the world. Of the 57 articles selected from the papers read before the local Societies, 25 relate to zoology, 22 to botany, 5 to geology, I to chemistry, and 4 to miscellaneous subjects. While of the titles of these papers we append a classified list, some few of them merit a more particular reference.

Mr. E. Meyrick contributes a third series of his descriptions of New Zealand Microlepidoptera,trcating this time of the Ecophoridæ. This is the principal family of the Tineina in New Zealand, as is also the case in Australia. Some 67 species are recorded, of which 55 are particularly described, but the total number of species it is thought will be much more considerable. In New Zealand the family constitutes about a sixth of the entire Microlepidoptera, in Australia it forms more than a fourth, whilst in Europe it is about a thirtieth. It seems strange that, while this family occupies so prominent a position in both New Zealand and Australia, no species as far as is yet known is common to both. Fourteen genera are found in New Zealand; of these ten are endemic, three occur also in Australia, and one is cosmopolitan. Of the three genera shared with Australia, two (Eulechria and Phlæopola) are large and typically Australian genera, represented in New Zealand by three species, obviously mere stragglers; the third (Trachypepla) is a typical New Zealand genus, probably of considerable extent, and is represented in Australia by two species only, evidently also stray wanderers. Of the ten endemic genera, none are very closely related to Australian forms. It would therefore appear that, while it is not improbable that a slight interchange of species has taken place at some not exceedingly remote period, it seems nearly certain that the group is of 